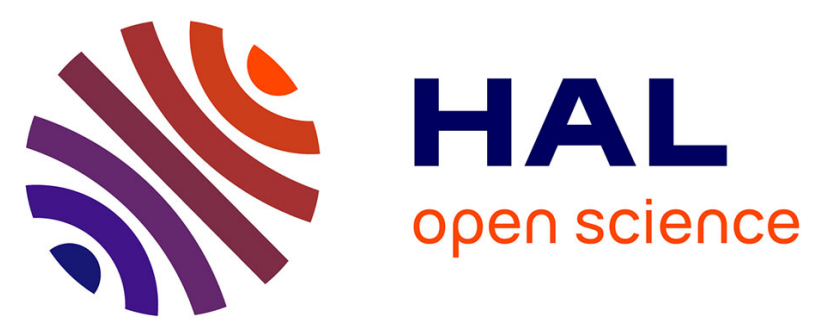

\title{
Quantitative analysis by micro-CT of damage during tensile test in a woven hemp/epoxy composite after water ageing
}

Amélie Perrier, Fabienne Touchard, Laurence Chocinski-Arnault, David Mellier

\section{To cite this version:}

Amélie Perrier, Fabienne Touchard, Laurence Chocinski-Arnault, David Mellier. Quantitative analysis by micro-CT of damage during tensile test in a woven hemp/epoxy composite after water ageing. Composites Part A: Applied Science and Manufacturing, 2017, 102, pp.18-27. 10.1016/j.compositesa.2017.07.018 . hal-02336904

\section{HAL Id: hal-02336904 https://hal.science/hal-02336904}

Submitted on 19 Jul 2020

HAL is a multi-disciplinary open access archive for the deposit and dissemination of scientific research documents, whether they are published or not. The documents may come from teaching and research institutions in France or abroad, or from public or private research centers.
L'archive ouverte pluridisciplinaire HAL, est destinée au dépôt et à la diffusion de documents scientifiques de niveau recherche, publiés ou non, émanant des établissements d'enseignement et de recherche français ou étrangers, des laboratoires publics ou privés. 


\title{
Quantitative analysis by micro-CT of damage during tensile test in a woven hemp/epoxy composite after water ageing
}

\author{
Amélie Perrier, Fabienne Touchard*, Laurence Chocinski-Arnault, David Mellier \\ Institut Pprime, CNRS-ISAE-ENSMA-Université de Poitiers UPR 3346, Département Physique et Mécanique des Matériaux, ENSMA 1 av Clément Ader, 86961 Futuroscope \\ Chasseneuil, France
}

\section{A R T I C L E I N F O}

\section{Article history:}

Received 18 May 2017

Accepted 18 July 2017

Available online 20 July 2017

\section{Keywords:}

A. Biocomposite

B. Environmental degradation

B. Transverse cracking

D. CT analysis

\begin{abstract}
A B S T R A C T
The influence of water ageing on the evolution of damage during tensile loading in woven hemp/epoxy composites is studied. First, the water uptakes of several types of samples are compared. Micro-CT observations show that, from the beginning of desorption but not during the water ageing, damage appears in the composites. At macroscopic scale, tensile tests reveal a significant modification of mechanical properties of the composite after water ageing. Then, an original test, combining tensile loading and X-ray microtomography, is performed on a \pm 45 hemp/epoxy composite material. The volume of damage inside two specimens (with and without water ageing) at several steps during a tensile test can be quantified. Results highlight significant differences in the evolution of the volume of damage between the two samples. This work shows how the mechanisms of deformation and damage of plant fibre composites are governed by their moisture exposure history.
\end{abstract}

(c) 2017 Elsevier Ltd. All rights reserved.

\section{Introduction}

Plant-based fibre composites present numerous advantages, notably good specific properties compared to those of glass fibre composites [1-3], which tend to be replaced. However, a crucial issue with plant fibre composites is their durability when they are subjected to moisture. Indeed, plant fibres are highly hydrophilic. The main component of plant fibres, cellulose, is a semicrystalline polysaccharide which gives the fibre its hydrophilic property with the high percentage of hydroxyl groups $(\mathrm{OH})$ that it contains [4]. Hemicellulose is the principal contributor to the moisture absorption due to its open structure containing hydroxyl $(\mathrm{OH})$ and acetyl $\left(\mathrm{C}_{2} \mathrm{H}_{3} \mathrm{O}\right)$ groups. The remaining main components, lignin and pectin, have only small influence on water absorption. In plant fibre composites, the fibres and the matrix have different affinities with water. This induces a decrease in interfacial characteristics compared to glass/polymer composites [5]. In a moist environment, a composite with plant-based reinforcement will have a higher decrease in its mechanical properties than a composite containing glass fibres, which absorb less water [6-8]. Indeed, in synthetic fibre composites, moisture absorption is essentially governed by the matrix whereas in plant fibre composites, it is mainly governed by fibres. This high sensitivity to moist

\footnotetext{
* Corresponding author.

E-mail address: fabienne.touchard@ensma.fr (F. Touchard).
}

environment constitutes, for the development of these materials, a real barrier which needs to be studied in order to use plant fibres as reliable and long lasting reinforcements in composite materials.

The water uptake in plant fibre composites is usually presented in literature as generating several local degradations. Damage can appear during the ageing but also after drying $[6,9,10]$. It has been described that water diffuses in plant fibre reinforced polymer composites by three different mechanisms [9]. The first one concerns the water molecules getting into the microgaps between polymer chains. The second one involves capillarity transport into the gaps and cracks at the fibre/matrix interfaces, which are created by poor wetting and impregnation defects between the two components during the composite manufacturing. The last one may involve transport of water by microcracks in the matrix arising from the swelling of fibres. Indeed, the absorbed water, by causing a swelling of the natural fibres, generates stresses at the fibre/matrix interface. Moreover, water-soluble substances can leach from the fibres [10]. When the composite dries, the decrease in fibre section due to the leaching and the matrix distortion caused by molecular relaxation [6], combined with the differential shrinkage between matrix and fibres, lead to the appearance of cracks at the fibre/matrix interface. In a previous work, we focused on the development of damage in a single hemp yarn composite after water ageing [11]. No quantification of damage developing after water ageing in the whole volume of a composite exists, to our knowledge, in literature. It constitutes a necessary information 
for the well understanding of eco-composite, thus a 3D investigation appears useful.

$\mathrm{X}$-ray microtomography is a non-contact and non-destructive technique which enables the reconstruction in 3D of a material, from images taken while the sample is rotated on an axis. As the constituents of a composite have different densities, their absorptions of X-rays are different and they can be easily distinguished from one another thanks to their grey levels on the pictures. High resolution can be reached and another advantage is that quantitative measurements can be done in three dimensions, thanks to many software programs developed for this technique.

Only few studies deal with the use of X-ray microtomography on plant fibre composites and they generally use it for a material characterisation purpose, as for example the measurement of orientation, distribution and dimension of short fibres in composites $[12,13]$, or the control of the presence of defects, including the porosity content $[14,15]$. One paper, to our knowledge, used this technique associated with mechanical tests in order to analyse the development of damage in a plant fibre composite under loading condition, without water ageing. Rask et al. [16] observed in situ the damage evolution in a unidirectional flax/polypropylene composite under tensile loading, with the help of synchrotron Xray tomography. With this device, a voxel size of $0.74 \mu \mathrm{m}$ could be reached and several types of damage could be differentiated (debonding at the fibre/matrix interface, cracks in the matrix and fibre failure).

In this work, the influence of water ageing on the evolution of mechanical damage in woven hemp yarn/epoxy composites is studied. First, the water absorption for several types of hemp/ epoxy composites is measured. Next, observation of the sample at desorption (i.e. when removed from water) is presented. The effect of the water ageing on the tensile properties of selected specimens is analysed and original testing, combining tensile test and X-ray microtomography, is performed. The analysis of the pictures enables us to quantify the volume of damage inside the material and to compare its evolution during tensile test, with and without water ageing.

\section{Materials and methods}

\subsection{Tested materials}

All the studied composite materials were made of seven plies of a woven hemp fabric impregnated with epoxy resin. Two different fabrics and two epoxy resins were used. The first hemp fabric, denoted Oleron, was a plain weave which had three yarns for each warp and weft strand (Fig. 1a), and had a fabric weight of $267 \pm 1 \mathrm{~g} / \mathrm{m}^{2}$. The yarns had a twist angle of $13 \pm 4^{\circ}$. The second fabric, denoted Brison, was a plain weave (Fig. 1b) which had a fabric weight of $290 \pm 6 \mathrm{~g} / \mathrm{m}^{2}$. The twist angle of the yarns was $18 \pm 5^{\circ}$. The first of the two matrices was a fully synthetic epoxy resin, Epolam 2020 (Axson Technologies), having a density of $1.16 \mathrm{~g} / \mathrm{cm}^{3}$ after curing [17]. The second one was a partially biobased resin, Greenpoxy 56 (Sicomin), containing 56\% of bio-based carbon atoms, with a density of $1.18 \mathrm{~g} / \mathrm{cm}^{3}$.

The composite plates were manufactured at the Pprime Institute, France, by an infusion process. The hemp fabrics were dried at $40{ }^{\circ} \mathrm{C}$ for $24 \mathrm{~h}$ before manufacturing. The composite plates made with the Epolam resin were cured with the following cycle: $24 \mathrm{~h}$ at ambient temperature, $3 \mathrm{~h}$ at $40^{\circ} \mathrm{C}, 2 \mathrm{~h}$ at $60^{\circ} \mathrm{C}, 2 \mathrm{~h}$ at $80^{\circ} \mathrm{C}$ and $4 \mathrm{~h}$ at $100{ }^{\circ} \mathrm{C}$, to achieve a cross-linkage as complete as possible. The plates made with the Greenpoxy resin were cured $24 \mathrm{~h}$ at ambient temperature, $24 \mathrm{~h}$ at $40^{\circ} \mathrm{C}, 16 \mathrm{~h}$ at $60^{\circ} \mathrm{C}, 8 \mathrm{~h}$ at $80^{\circ} \mathrm{C}$ and $30 \mathrm{~min}$ at $95^{\circ} \mathrm{C}$. The optimisation of these curing cycles was based on the neat resins and the final glass transition temperature was $89 \pm 2{ }^{\circ} \mathrm{C}$ for Epolam 2020 and $83 \pm 2{ }^{\circ} \mathrm{C}$ for Greenpoxy 56. From the plates, rectangular specimens were cut with the dimensions of $150 \times 20 \mathrm{~mm}^{2}$, the longitudinal axis being denoted $\mathrm{x}$. Some Oleron/Epolam specimens were cut with the warp direction parallel to the $x$ axis (noted $0 / 90$ ), and others in a way that they were oriented with an angle of $45^{\circ}$ with respect to the $\mathrm{x}$ direction (noted \pm 45 ).

\subsection{Water ageing}

In order to study the influence of moisture, a set of specimens was immersed in water at ambient temperature. Several times during the first day of ageing, and then less and less frequently, samples were removed from water, wiped with paper towel to remove any excess of water on the surface, and weighted with a Sartorius RC210D precision balance (with a $0.01 \mathrm{mg}$ accuracy). Water uptake $M_{t}$ was obtained from Eq. (1),

$M_{t}=\frac{m_{t}-m_{0}}{m_{0}} \times 100$

where $m_{t}$ is the mass of the sample at time $t$, and $m_{0}$ the initial mass.

The diffusion of water in a solid is usually described by the Fick's second law of diffusion. The sorption increases linearly with the square root of time in a first step and then reaches a saturation plateau. For short times, the sorption can be described by the Eq. (2), as proposed by Shen and Springer [18]:

$$
\frac{M_{t}}{M_{\infty}}=1-\frac{8}{\pi^{2}} \sum_{j=0}^{\infty} \frac{1}{(2 j+1)^{2}} \exp \left[-\frac{(2 j+1)^{2} \pi^{2} D t}{h^{2}}\right]
$$

where $M_{\infty}$ is the water uptake at saturation, $h$ is the sample thickness and $D$ the diffusion coefficient. (a)

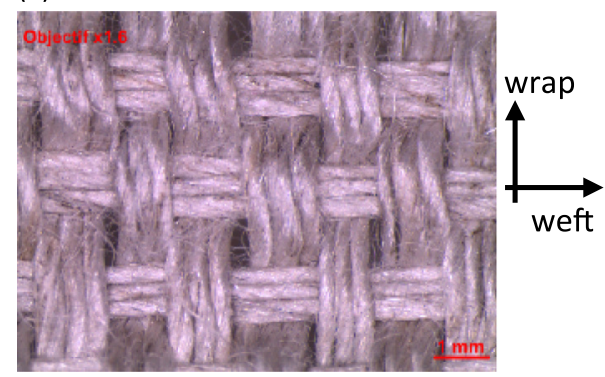

(b)

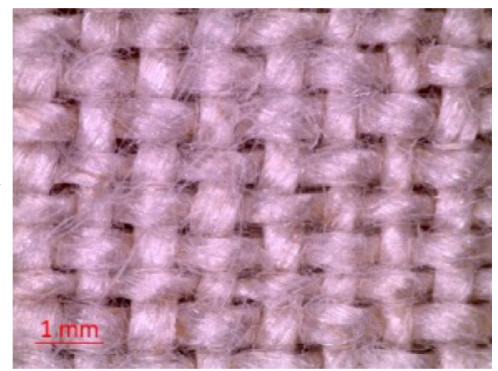

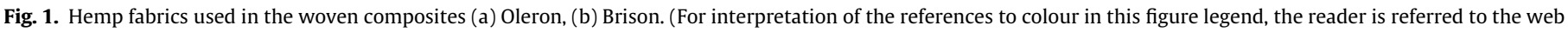
version of this article.) 
(a)

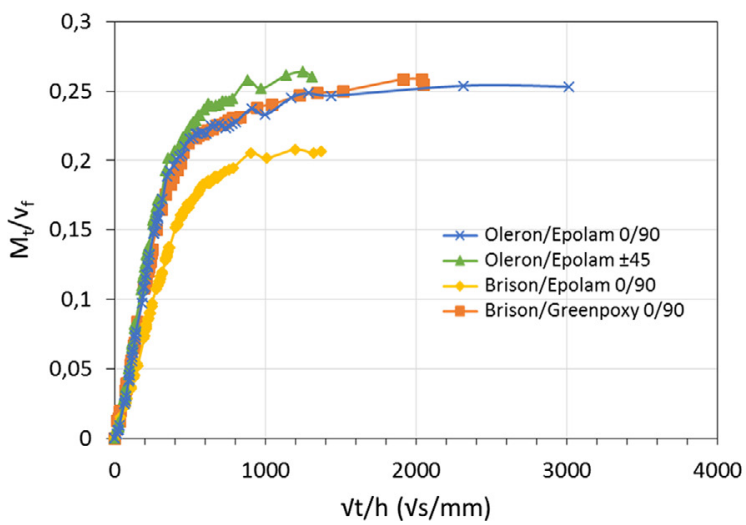

(b)

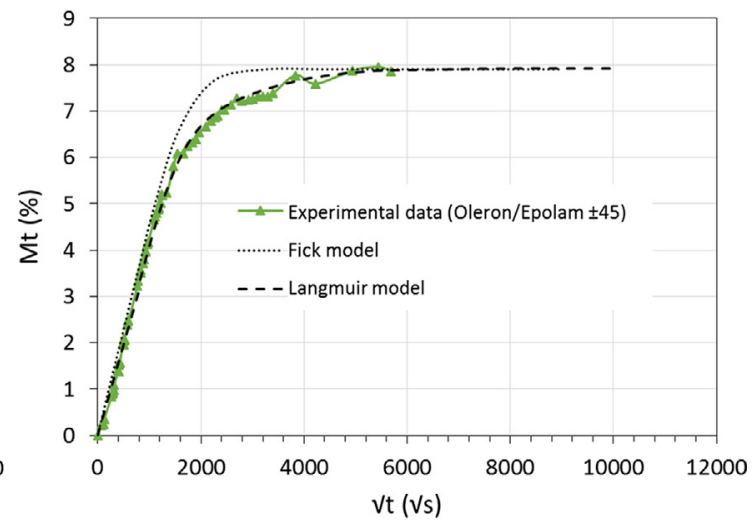

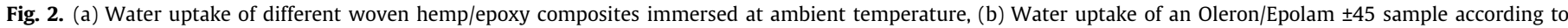
Fickian and Langmuir-type models. (For interpretation of the references to colour in this figure legend, the reader is referred to the web version of this article.)

Table 1

Diffusion parameters of the studied hemp/epoxy composites obtained by the Fickian model.

\begin{tabular}{|c|c|c|c|c|c|}
\hline Material & $\boldsymbol{M}_{\infty}(\%)$ & $\boldsymbol{M}_{\infty} / \mathrm{V}_{\mathrm{f}}$ & $\mathrm{k}\left(10^{-3} \% . \mathrm{s}^{-0.5}\right)$ & $\mathrm{h}(\mathrm{mm})$ & $\mathrm{D}\left(10^{-6} \mathrm{~mm}^{2} / \mathrm{s}\right)$ \\
\hline Oleron/Epolam 0/90 & $7.75 \pm 0.34$ & $0.245 \pm 0.009$ & $4.898 \pm 0.152$ & $4.35 \pm 0.04$ & $1.50 \pm 0.27$ \\
\hline Oleron/Epolam \pm 45 & $7.58 \pm 0.04$ & $0.247 \pm 0.013$ & $4.728 \pm 0.106$ & $4.30 \pm 0.07$ & $1.41 \pm 0.15$ \\
\hline Brison/Epolam 0/90 & $6.73 \pm 0.16$ & $0.203 \pm 0.004$ & $3.228 \pm 0.302$ & $4.09 \pm 0.15$ & $0.75 \pm 0.16$ \\
\hline Brison/Greenpoxy 0/90 & $7.60 \pm 0.16$ & $0.250 \pm 0.006$ & $4.603 \pm 0.253$ & $3.94 \pm 0.07$ & $1.12 \pm 0.09$ \\
\hline
\end{tabular}

Table 2

Diffusion parameters of the studied hemp/epoxy composites obtained by the Langmuir-type model.

\begin{tabular}{lll}
\hline Material & $\beta\left(10^{-8} \mathrm{~s}^{-1}\right)$ & $\gamma\left(10^{-8} \mathrm{~s}^{-1}\right)$ \\
\hline Oleron/Epolam 0/90 & $8.65 \pm 4.04$ & $3.31 \pm 2.26$ \\
Oleron/Epolam \pm 45 & $27.7 \pm 19.7$ & $25.7 \pm 30.4$ \\
Brison/Epolam 0/90 & $17.3 \pm 3.17$ & $6.68 \pm 2.63$ \\
Brison/Greenpoxy 0/90 & $9.87 \pm 4.60$ & $2.86 \pm 1.72$ \\
\hline
\end{tabular}

An approximation of the Eq. (2) for short times is given by the Eq. (3).

$\frac{M_{t}}{M_{\infty}}=\frac{4}{h} \sqrt{\frac{D t}{\pi}}$

This equation gives the expression of the diffusion coefficient $D$, equal to:

$D=\frac{\pi}{\left(4 M_{\infty}\right)^{2}}\left(\frac{M_{t} h}{\sqrt{t}}\right)^{2}=\pi\left(\frac{k}{4 M_{\infty}}\right)^{2}$

$k$ being the slope of the linear part of the $M_{t}=f(\sqrt{t} / h)$ curve.

In some cases the sorption does not follow a Fickian behaviour. A common approach to describe this behaviour is the Langmuir-type absorption. This model is based on the hypothesis that water exists in two forms inside the solid: bound water and free water. The Langmuir-type model associates to each molecule of each type a probability $\beta$ that a bound water molecule becomes free and a probability $\gamma$ that a free molecule becomes bound [19]. Then, the water sorption can be approximated, for short times, by the Eq. (5) [19]:

$M_{t}=\frac{4}{\pi^{\frac{3}{2}}}\left[\frac{\beta}{\gamma+\beta} M_{\infty}\right] \sqrt{\kappa t}$

with $\kappa=\frac{\pi^{2} D}{h^{2}}$, and for long times $\left(D t / h^{2}>0.05\right)$ by the Eq. (6), as proposed by Bonniau and Bunsell [20]:

$M_{t}=M_{\infty}\left[1-\frac{\gamma}{\gamma+\beta} e^{-\beta t}-\frac{\beta}{\gamma+\beta} \frac{8}{\pi^{2}} e^{-\frac{D t}{h^{2}} \pi^{2}}\right]$

\subsection{Micro-CT apparatus}

Image acquisition was performed at Pprime Institute using an UltraTom CT scanner manufactured by RX Solutions (France). A $18 \mu \mathrm{m}$ resolution has been used in this work, with an accelerating voltage of $70 \mathrm{kV}$ and a beam current of $141 \mathrm{~mA}$. The flat panel detector used in this study has 1920 x 1536 pixels with a pixel size

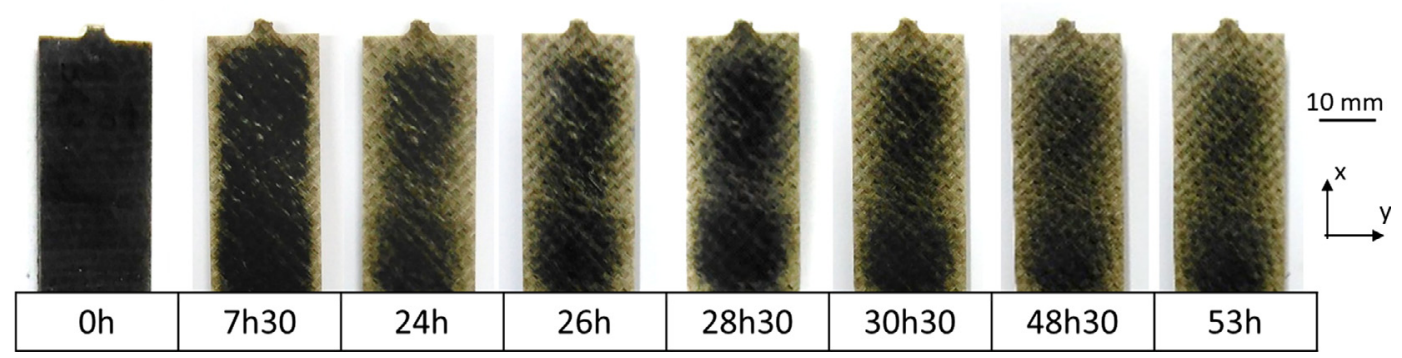

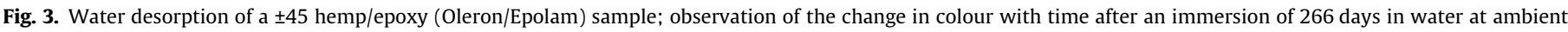
temperature. (For interpretation of the references to colour in this figure legend, the reader is referred to the web version of this article.) 


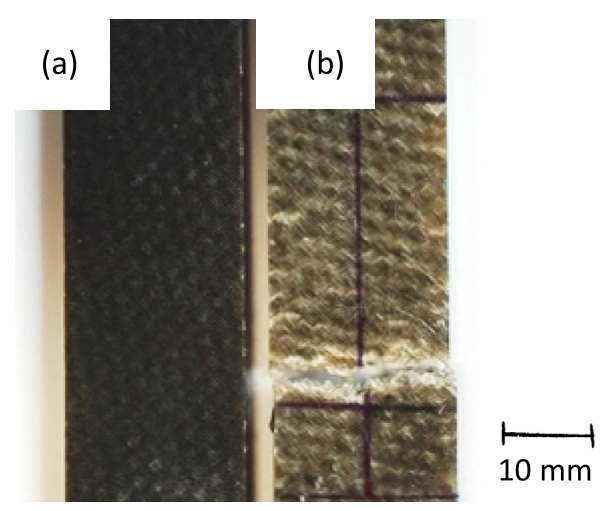

Fig. 4. Gauge length of \pm 45 non aged hemp/epoxy (Oleron/Epolam) samples (a) virgin and (b) after a tensile test up to failure. (For interpretation of the references to colour in this figure legend, the reader is referred to the web version of this article.)

of $127 \mathrm{~mm}$. This X-ray detector consists in an X-ray CsI scintillator screen which is settled on an amorphous silicon layer. The image acquisition time was about $2 \mathrm{~h}$ per specimen. For 3D reconstruction, images were acquired from 1120 rotation views over $360^{\circ}$ of rotation $\left(0.32^{\circ}\right.$ rotation step). The reconstruction was performed using an algorithm based on the filtered back-projection procedure for Feldkamp cone beam geometry.

\subsection{Repeated progressive tensile loading}

To observe the formation and growth of cracks in woven hemp composites, \pm 45 Oleron/Epolam specimens were tested with a repeated progressive loading test, coupled with X-ray microtomography. First, the sample was loaded in a tensile testing machine until a low stress level. Then, it was unloaded and removed from the testing machine to perform a micro-CT analysis. After that, the sample was mounted again in the testing machine and loaded to a stress level higher than the previous one. The whole procedure was repeated in this way until the specimen failure.

Tests were made on an INSTRON 1195 tensile testing machine with a load cell of $\pm 50 \mathrm{kN}$, and a crosshead speed of $0.5 \mathrm{~mm} / \mathrm{min}$. A $12.5 \mathrm{~mm}$ extensometer was used to measure the longitudinal strain (in the $\mathrm{x}$ direction). Each specimen extremity was clamped by the jaws of the test machine over a length of $30 \mathrm{~mm}$.

\section{Results and discussion}

\subsection{Water uptake}

The absorption curves of the specimens immersed in water are shown in Fig. 2a. Each curve is one example for each kind of hemp/ epoxy composites. In order to get rid of the influence of the volume fraction of fibres, which can be different between the samples, the water uptake is divided by the volume fraction of fibres. In the same way, the square root of time is divided by the thickness of each specimen to avoid differences in the water uptake caused by variations in the thicknesses of the samples. It appears from these experimental data that the resin used has an influence on the amount of water which the material can absorb. Indeed, the composite with the Greenpoxy matrix (Brison/Greenpoxy) absorbs more water at saturation $\left(M_{\infty} / v_{f}\right.$ ratio of 0.258$)$ than the composite with Epolam matrix (Brison/Epolam), with a $M_{\infty} / v_{f}$ ratio of 0.207. In regards to the mean values obtained from several samples of each material (Table 1), the same observation is made.

The type of reinforcement has also an influence, as the comparison between the Oleron/Epolam and the Brison/Epolam specimens shows. The Oleron fabric seems to let the composite absorb more water. This difference can be explained by the different yarns and fabric architectures which were used. The Oleron fabric is less closely woven than the Brison fabric (Fig. 1), and its yarns have a lower twist angle; this could make easier the absorption of a higher amount of water. The water absorptions of Oleron/Epolam 0/90 and Oleron/Epolam \pm 45 specimens are close, in accordance with the fact that the same material is involved. The smaller absorption of the Brison fabric seems balanced by the high absorption of the Greenpoxy matrix, resulting in the same absorption for the Brison/Greenpoxy 0/90 and the Oleron/Epolam 0/90 (ratio of 0.258 and 0.254 , respectively). The number of days needed to reach a saturation plateau change also with the materials. The two specimens Brison/Greenpoxy 0/90 and Oleron/Epolam 0/90 are saturated after around 600 days, whereas the Brison/Epolam 0/90 and Oleron/Epolam \pm 45 need 262 and 342 days, respectively. Fig. $2 \mathrm{~b}$ displays for a \pm 45 Oleron/Epolam specimen the superposition of the experimental curve, the Fickian and the Langmuir-type absorption models.

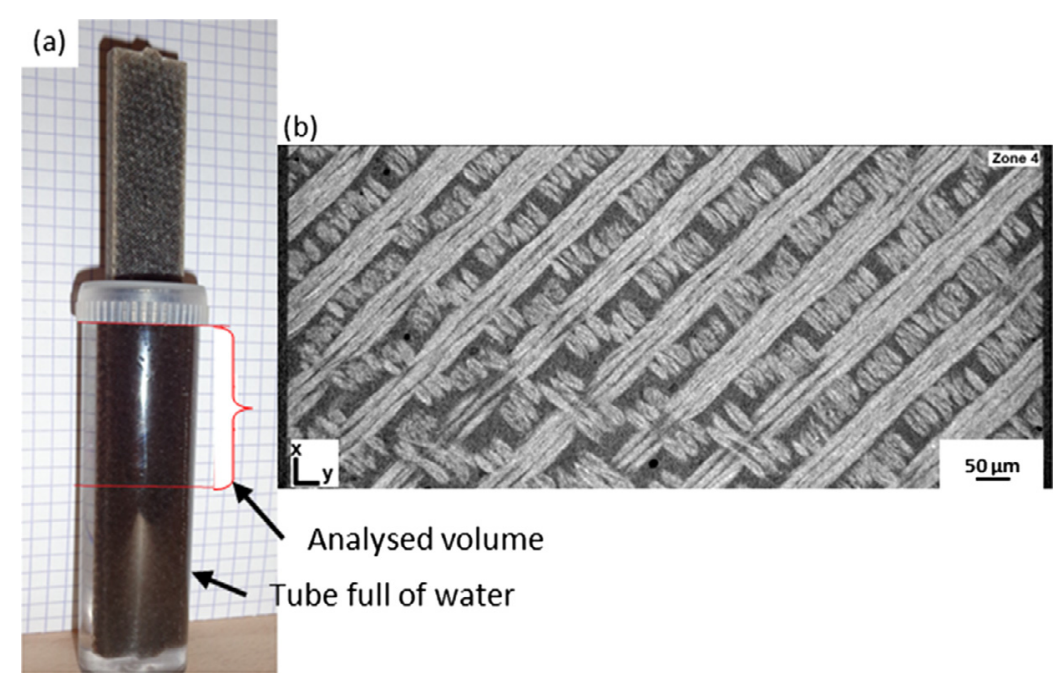

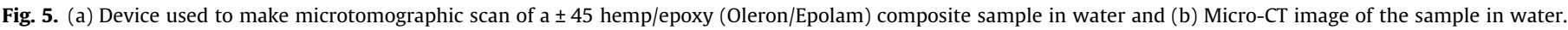
(For interpretation of the references to colour in this figure legend, the reader is referred to the web version of this article.) 


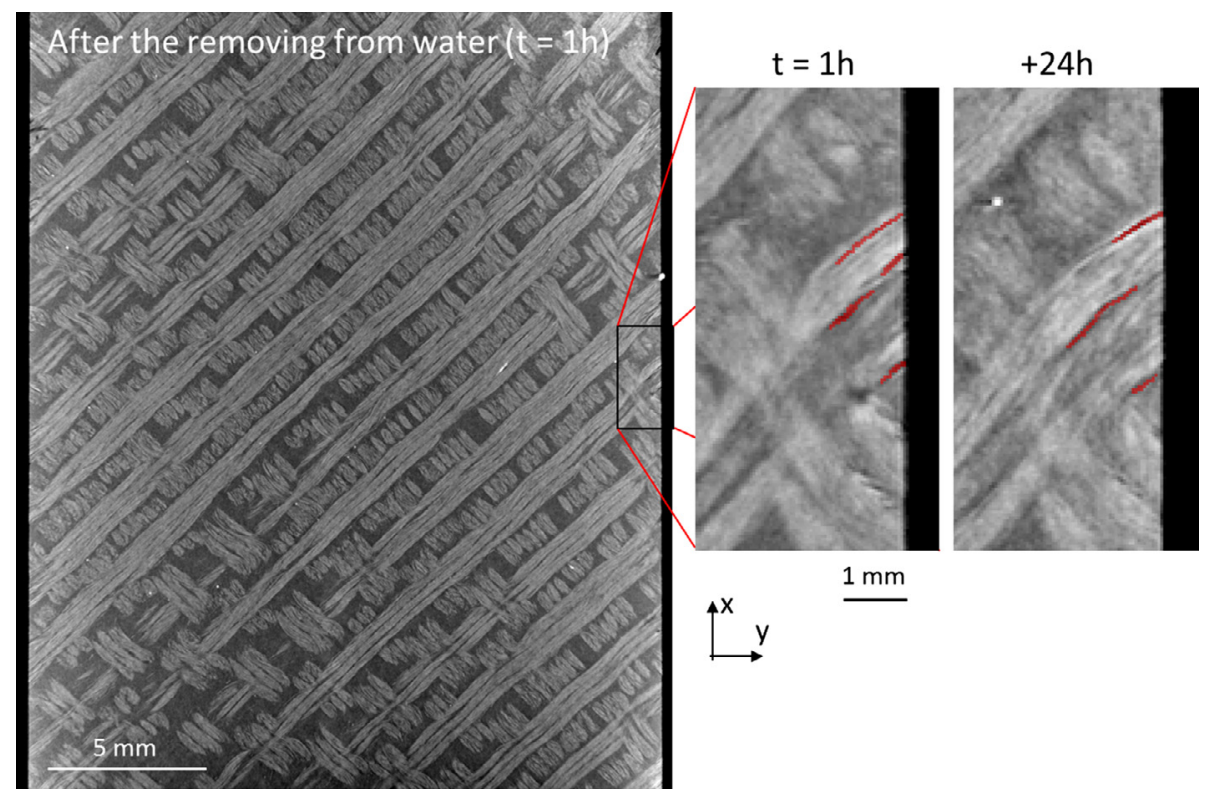

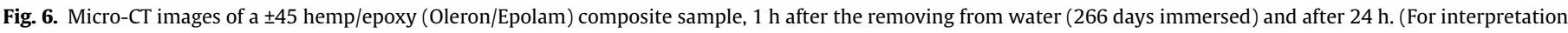
of the references to colour in this figure legend, the reader is referred to the web version of this article.)

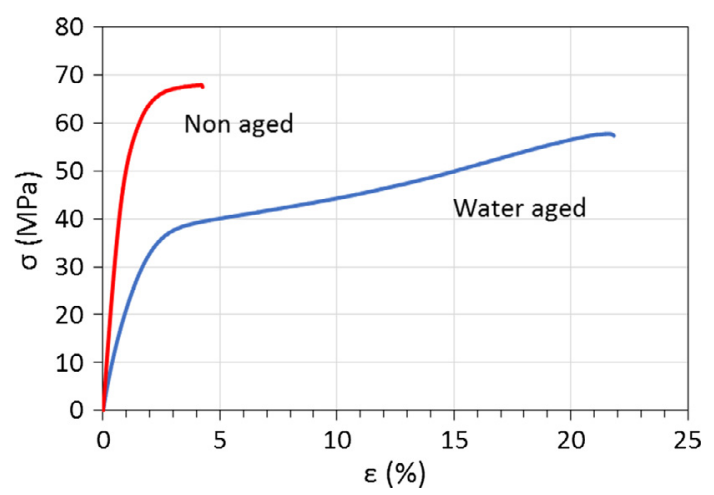

Fig. 7. Experimental tensile stress-strain curves of \pm 45 non-aged and water-aged (366 days) hemp/epoxy (Oleron/Epolam) composites. (For interpretation of the references to colour in this figure legend, the reader is referred to the web version of this article.)

The sample does not follow a Fickian absorption, whereas it appears that the Langmuir-type model is more suitable to describe the kinetic of absorption of the composite sample. This constitutes an example for one specimen, but the same observation was made with the others.

Although experimental data do not obey the Fickian absorption, it still can be used to calculate diffusion coefficients. Indeed, for short times of ageing, the initial portion of the curve, linearly proportional to the square root of time, is successfully described by this law. From Table 1 , it is shown that the Brison/ Epolam 0/90 composite has the lowest diffusion coefficient, with $0.75 \pm 0.16 \times 10^{-6} \mathrm{~mm}^{2} / \mathrm{s}$. This composite is also the one which absorbs the less among the materials studied here, as seen previously. The parameters computed from the Langmuir-type absorption model are presented in Table 2 .

\subsection{Water desorption}

When the specimens were removed from water, after they reached their saturated level, a progressive whitening of the composite was observed. The evolution of the colour of a \pm 45 Oleron/ Epolam sample is presented in Fig. 3, for different durations at ambient air. This specimen was previously aged in water for 266 days at ambient temperature. The whitening started from the edges, and then propagated towards the centre of the sample. Due to the orientation of the plies, every yarn inside the sample has its both ends coincident with two edges of the specimen. As plant fibres are very hydrophilic, the edges are privileged locations for water absorption but also desorption, unlike the two faces which have epoxy resin as external layers.

Fig. 4 shows the gauge length of a virgin specimen (Fig. 4a) and a non-aged specimen after a tensile test (Fig. 4b). It can be noticed that the colour of the material after the tensile test is the same as the colour of the water-aged sample during desorption. Thus, a mechanical explanation can be at the origin of the whitening: it could come from damage.

In order to verify whether the damage, which was observed at desorption, already exists during the water ageing, $\mathrm{a} \pm 45$ Oleron/ Epolam specimen immersed in water for 117 days (93\% of $M_{\infty}$ ) was analysed by micro-CT while it was still in water. A specific device which reduced the amount of water crossed by the X-rays was used (Fig. 5a). In this way, sufficient visibility of the material could be achieved. The strands, made of three yarns and oriented at $45^{\circ}$ with respect to the tensile direction can be recognized in the Fig. 5b. No damage was observed in the obtained pictures

Table 3

Maximum applied stress level (in MPa) for each loading cycle of the progressive repeated tensile loading tests.

\begin{tabular}{|c|c|c|c|c|c|c|c|c|c|}
\hline & \multicolumn{9}{|c|}{ Loading cycle } \\
\hline & 1 & 2 & 3 & 4 & 5 & 6 & 7 & 8 & 9 \\
\hline Non-aged sample & 45 & 61 & 65 & 66 & 64 & & & & \\
\hline Water-aged sample & 21 & 35 & 40 & 44 & 46 & 48 & 51 & 53 & 52 \\
\hline
\end{tabular}




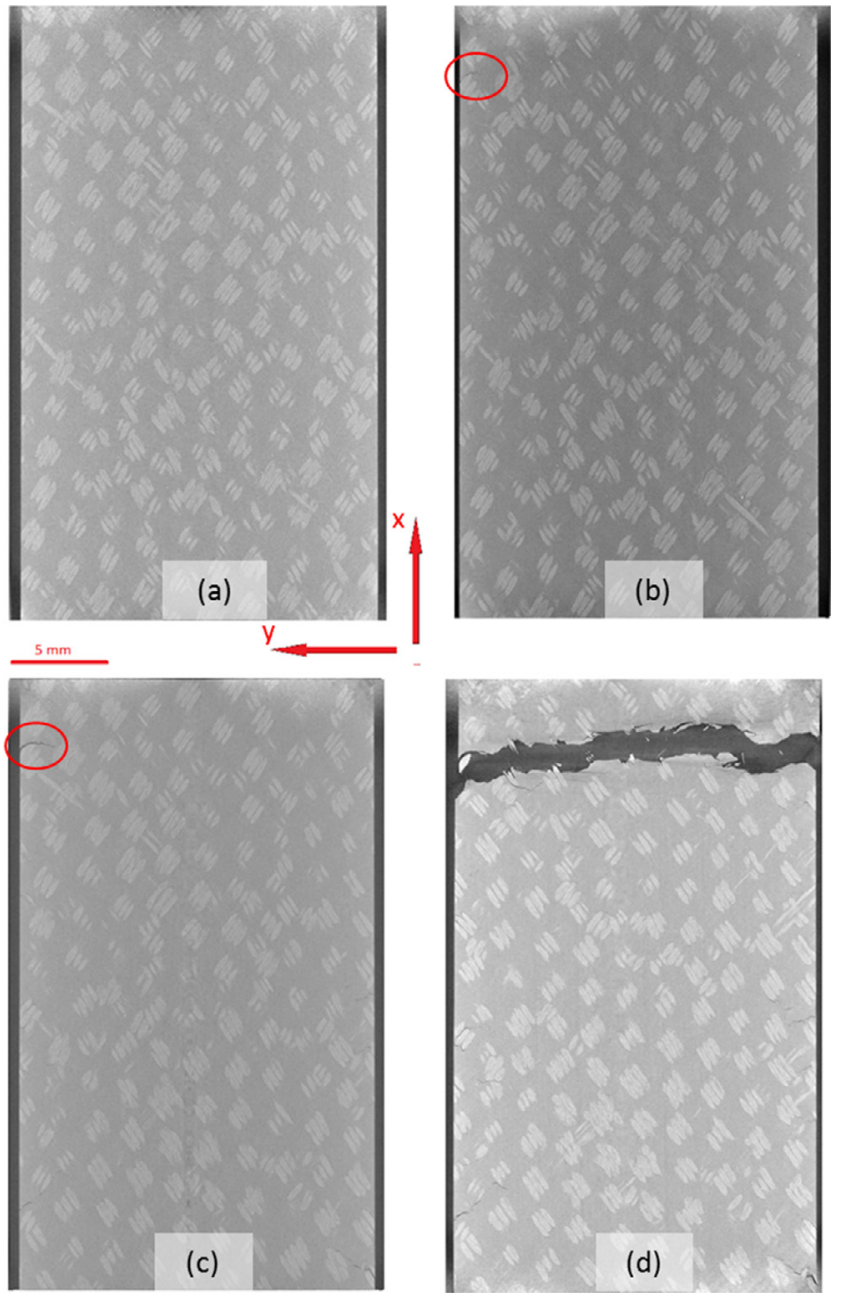

Fig. 8. Micro-CT images of the \pm 45 non-aged hemp/epoxy (Oleron/Epolam) sample (a) at the initial state and after loading at (b) $65 \mathrm{MPa}$, (c) $66 \mathrm{MPa}$ and (d) after failure. (For interpretation of the references to colour in this figure legend, the reader is referred to the web version of this article.)

(Fig. 5b). This tends to show that damage appeared only at desorption. Further investigations on the development of damage at desorption at the yarn scale were also made in this project and confirm this observation [11].

A specimen of \pm 45 hemp/epoxy (Oleron/Epolam) composite was immersed in water during 266 days and then was analysed by micro-CT after its removing from water, without any loading applied on it. One can see in Fig. 6 some cracks running along the hemp yarns on the edge of the specimen. The red lines at $\mathrm{t}=1 \mathrm{~h}$ (duration needed for the micro-CT acquisition) in Fig. 6 indicate the location of some of them. This result shows that the whitening observed after the removing from water is due to damage, which does not appear during immersion but only at the desorption. Fig. 3 showed that the damage which propagates in a sample is quite advanced after $24 \mathrm{~h}$. In the micro-CT pictures, the evolution of the damage, between $1 \mathrm{~h}$ and $24 \mathrm{~h}$, is not easily visible. This can be explained by the fact that the resolution of the pictures is $18 \mu \mathrm{m}$ for 1 pixel, which makes difficult the detection of the smallest cracks.

\subsection{Effect on mechanical properties}

Tensile tests performed on the different hemp/epoxy samples have shown that the \pm 45 Oleron/Epolam samples have the highest sensitivity to the water ageing. Thus, the following results will be focused on the behaviour of this composite, with or without water ageing. Fig. 7 presents the typical tensile test curves for two specimens, one being non-aged and the other one being aged for 366 days in water. The water ageing caused a decrease in the Young's modulus from $6.04 \pm 0.25 \mathrm{GPa}$ to $3.10 \pm 0.63 \mathrm{GPa}$. The tensile stress at failure decreased from $66 \pm 3 \mathrm{MPa}$ to $57 \pm 4 \mathrm{MPa}$ and the strain at break $\left(\varepsilon^{R}\right)$ increased from $5.9 \pm 0.9 \%$ to $22 \pm 0.1 \%$. These evolutions are consistent with other studies which concern the influence of water ageing on the mechanical properties of natural fibre composites at macroscopic scale, for example with hemp $[9,21,22]$, flax [7,23] or other bio-based reinforcements [24,25]. At the whole composite scale, a decrease in Young's modulus and tensile stress at failure, and an increase in elongation at break are generally noticed, attributed to the plasticising effect of water on the resin.

\subsection{Damage analysis}

\subsubsection{Micro-CT observations}

In order to better understand the development of damage during tensile tests in this eco-composite with and without water ageing, progressive repeated tensile loading tests combined with micro-CT were performed until the failure of the specimens. A non-aged and a water-aged (for 266 days) \pm 45 Oleron/Epolam specimens were tested. The non-aged sample was submitted to five loading cycles until failure, and the water-aged sample to nine cycles. Table 3 presents the maximum stress levels reached for every loading cycles applied to the two specimens. It has to be noted that the tensile stress at failure (at the last loading cycle) is slightly lower than the stress level reached at the previous cycle, for both specimens. In the next paragraphs of the document, the ultimate strength $\left(\sigma_{\mathrm{u}}\right)$ will refer, for each specimen, to the highest stress level reached during the whole repeated progressive tensile loading test.

After each loading cycle, the samples were scanned in the micro-tomograph. Fig. 8 shows the pictures obtained with microCT of the non-aged sample for several loading cycles. The displayed pictures correspond to a same area in the specimen, but variations in the position of the sample in the microtomograph make them slightly different. At the initial state (i.e. before tensile loading), no damage could be seen in the specimen (Fig. 8a). A crack was detected in the observed plane after the third loading cycle, corresponding to a maximum applied stress of $65 \mathrm{MPa}$, highlighted by the red cycle (Fig. 8b). This crack grew during the following loading cycle (Fig. 8c): it became longer and wider. Finally, it led to the failure of the composite during the fifth cycle, for an applied stress level of $64 \mathrm{MPa}$ (Fig. 8d).

For the water-aged specimen, the micro-CT pictures in Fig. 9 show, in the observed plane and with this resolution $(18 \mu \mathrm{m})$, that cracks appeared at the end of the fifth loading cycle (maximum applied stress of $46 \mathrm{MPa}$ ). Some of them are highlighted by red circles in Fig. 9b. There were only few of them and few visible at the beginning, but they progressively developed with the following loading cycles (Fig. 9d and e). Their number was a lot higher than in the non-aged sample. Finally, the failure occurred in a weak area of the specimen which let some cracks joint from an edge to another (Fig. 9f).

\subsubsection{Measurement of the volume of damage}

One of the interest of micro-CT images is that they can be combined to reconstruct the entire volume of the analysed sample. The analysis of this volume can give quantitative information about the development of damage after each loading cycle in the two specimens presented in this work. Fig. 10 shows a 3D view of the non-aged sample, as well as detected cracks (in red) at the end of the third and fourth loading cycles (at $99 \%$ and $100 \%$ of $\sigma_{\mathrm{u}}$, 

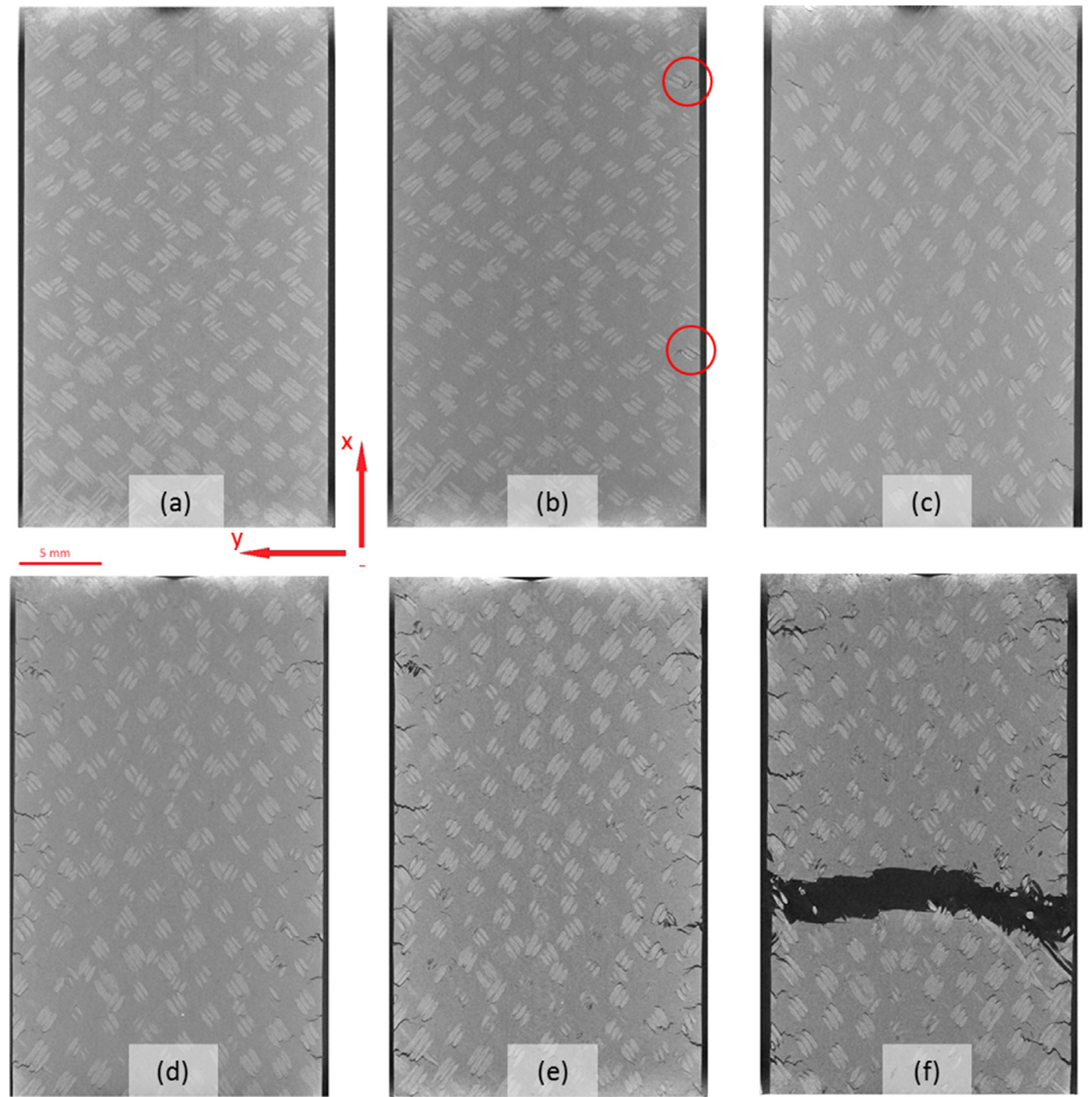

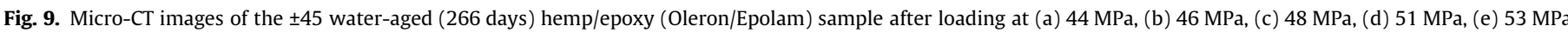
and (f) after failure. (For interpretation of the references to colour in this figure legend, the reader is referred to the web version of this article.)
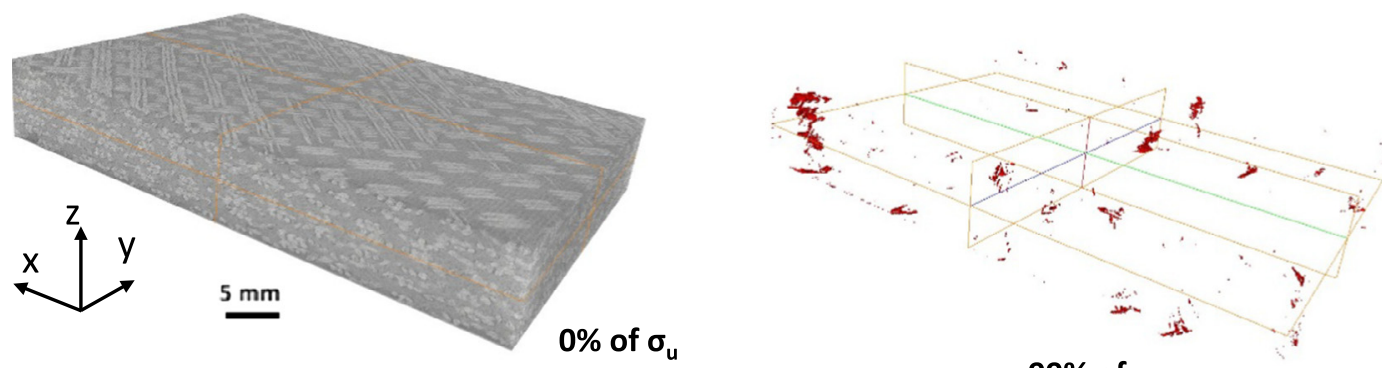

$99 \%$ of $\sigma_{u}$

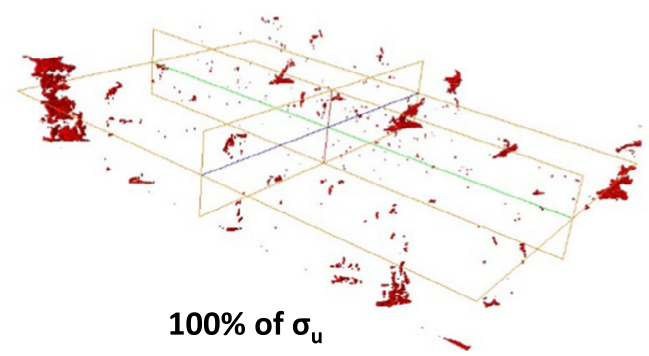

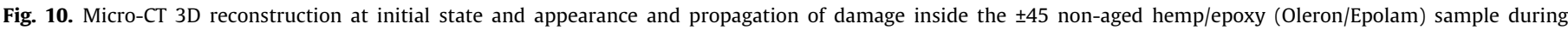
repeated progressive tensile loading test. (For interpretation of the references to colour in this figure legend, the reader is referred to the web version of this article.) 

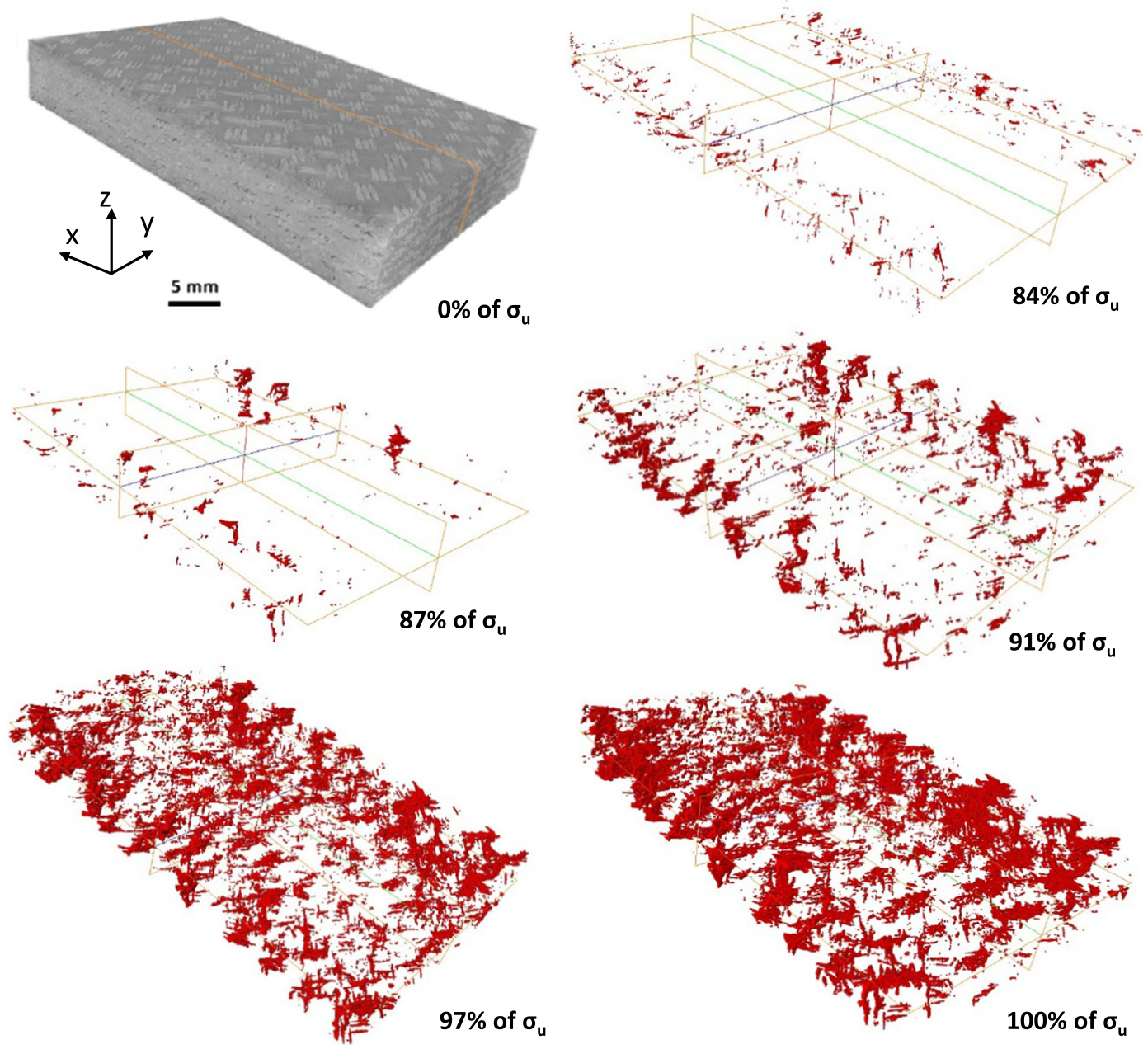

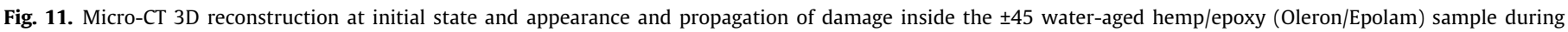
repeated progressive tensile loading test. (For interpretation of the references to colour in this figure legend, the reader is referred to the web version of this article.)

respectively). The cracks were localized and stood mainly along the edges of the specimen. At the fourth cycle, the previously created cracks increased and new ones appeared, notably in the centre of the sample.

Fig. 11 presents the $3 \mathrm{D}$ view of the water aged specimen. The propagation of the cracks, which are more numerous, is clearly visible in the volume. Up to the fourth cycle ( $84 \%$ of $\sigma_{\mathrm{u}}$ ), the cracks stayed located on the edges of the specimen. After the following loading cycle $\left(87 \%\right.$ of $\left.\sigma_{u}\right)$, the cracks on the edges propagated and new ones appeared inside the material, helped by the mechanical loading. Then, they developed during the following cycles and are distributed in the whole volume.

The quantification of this damage was made from the micro-CT pictures with the Avizo software. In each 3D representation, the voxels associated with damage were separated from the voxels attributed to the material, containing the fibres and matrix. Obtained results cannot be taken as absolute values but are used for comparison. Indeed, some cracks do not have a grey level sufficiently dark to be qualified as cracks by the image analysis, and thus are assimilated with the composite material. On the opposite, undamaged dark areas can be associated with cracks. Moreover, the analysed volume can vary, depending on how the image had been trimmed (the external part of the volume which contains external areas and/or artefacts were not taken into account in the analysis); thus, the ratio between the volume of damage and the total studied volume of the material will be used for the comparison between the two samples.

The studied volumes of the composites and the volume of damage measured for each loading cycle are presented in Tables 4 and 5 for the non-aged and the water-aged samples, respectively. One can see, in accordance with the observations made on the micro-CT pictures, that the relative volume of damage increases with the maximum applied stress for both samples. However, an anomaly is found at the second loading cycle of the non-aged sample (Table 4), for which the relative volume of damage is slightly lower than the one of the previous cycle $\left(1.08 \times 10^{-6}\right.$ vs $\left.1.45 \times 10^{-6}\right)$, whereas it should be logically higher. Indeed, when cracks are thin, during first loading cycles, they are less easily detectable. This shows the limit of the sensitivity of the method. It has also to be noted that the volume analysis of damage could not be conducted on samples after failure.

Finally, the results obtained at each loading level during the tensile tests on both specimens enable us to quantify the influence of the water ageing on the development of damage. The relative volume of damage is higher for the water-aged specimen than for the non-aged one. At the initial state, it is already 40 times higher than in the non-aged sample. At the last analysed cycle, the relative volume of damage is equal to $8320 \times 10^{-6}$ for the aged specimen and to $397 \times 10^{-6}$ for the non-aged specimen. Moreover, the aged sample has, just before failure, a volume of damage of 
Table 4

Volume measurements obtained by micro-CT analysis for \pm 45 non-aged hemp/epoxy (Oleron/Epolam) sample at each loading level during tensile test.

\begin{tabular}{|c|c|c|c|c|c|}
\hline Loading cycle & Initial & 1 & 2 & 3 & 4 \\
\hline$\%$ of $\sigma_{\mathrm{u}}$ & 0 & 68 & 93 & 99 & 100 \\
\hline $\mathrm{V}_{\text {material }}\left(\mathrm{mm}^{3}\right)$ & 2549.75 & 2497.06 & 2453.07 & 2490.06 & 2471.64 \\
\hline $\mathrm{V}_{\text {damage }}\left(\mathrm{mm}^{3}\right)$ & $<0.001$ & 0.004 & 0.003 & 0.202 & 0.982 \\
\hline $\mathrm{V}_{\text {total }}\left(\mathrm{mm}^{3}\right)$ & 2549.75 & 2497.07 & 2453.08 & 2490.26 & 2472.62 \\
\hline$\frac{V_{\text {damage }}}{V_{\text {total }}}\left(\times 10^{-6}\right)$ & 0.178 & 1.45 & 1.08 & 81.2 & 397 \\
\hline
\end{tabular}

Table 5

Volume measurements obtained by micro-CT analysis for \pm 45 water-aged hemp/epoxy (Oleron/Epolam) sample at each loading level during tensile test.

\begin{tabular}{|c|c|c|c|c|c|c|c|c|c|}
\hline Loading cycle & Initial & 1 & 2 & 3 & 4 & 5 & 6 & 7 & 8 \\
\hline$\%$ of $\sigma_{u}$ & 0 & 40 & 65 & 75 & 84 & 87 & 91 & 97 & 100 \\
\hline $\mathrm{V}_{\text {material }}\left(\mathrm{mm}^{3}\right)$ & 2747.29 & 2686.21 & 2554.15 & 2584.26 & 2213.84 & 2588.75 & 2516.31 & 2477.81 & 2437.71 \\
\hline$V_{\text {damage }}\left(\mathrm{mm}^{3}\right)$ & 0.019 & 0.027 & 0.037 & 0.044 & 0.137 & 0.703 & 3.862 & 14.171 & 20.441 \\
\hline $\mathrm{V}_{\text {total }}\left(\mathrm{mm}^{3}\right)$ & 2747.30 & 2686.24 & 2554.19 & 2584.300 & 2213.98 & 2589.46 & 2520.17 & 2491.98 & 2458.15 \\
\hline$\frac{v_{\text {damage }}}{V_{\text {total }}}\left(\times 10^{-6}\right)$ & 6.79 & 9.90 & 14.5 & 17.1 & 61.8 & 271 & 1530 & 5690 & 8320 \\
\hline
\end{tabular}

(a)

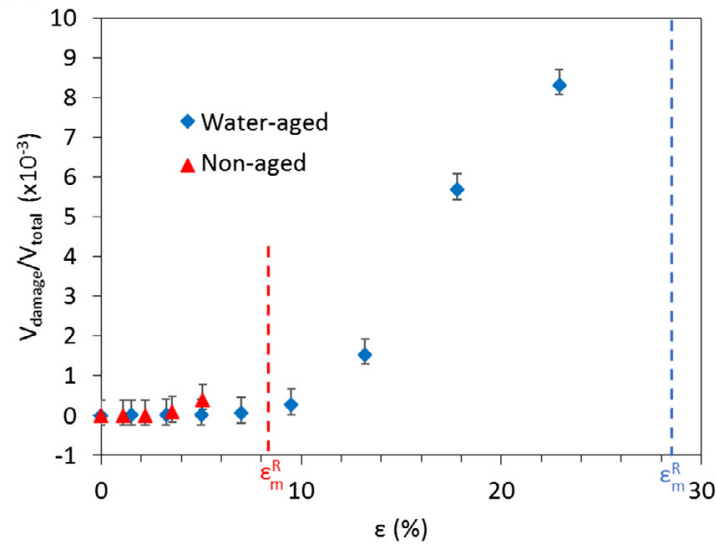

(b)

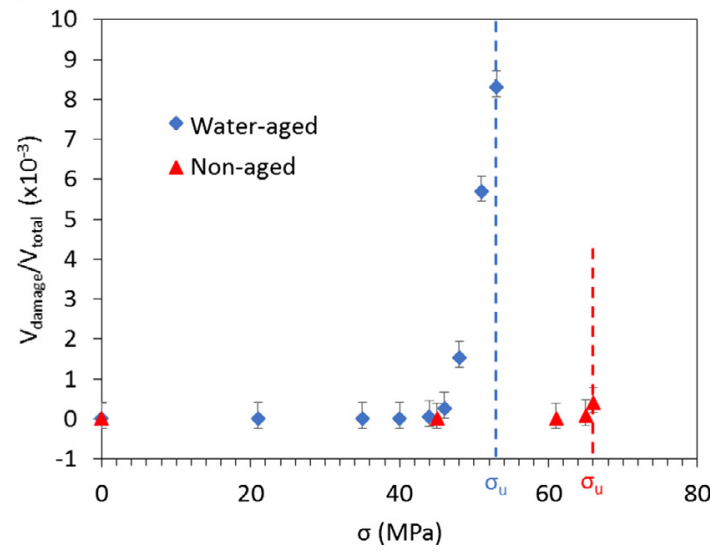

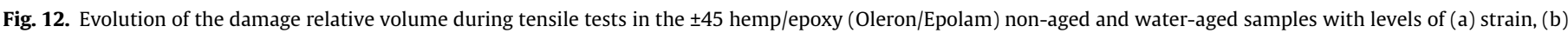
stress. (For interpretation of the references to colour in this figure legend, the reader is referred to the web version of this article.)

$20 \mathrm{~mm}^{3}$ whereas the non-aged one has a volume of damage lower than $1 \mathrm{~mm}^{3}$.

Fig. 12a shows the relative volume of damage in relation with the strain given by the tensile testing machine. The values of the strains at break (noted $\varepsilon_{\mathrm{m}}^{\mathrm{R}}$ ) are indicated with the dotted lines. One can see that the mechanisms of deformation of the two samples are clearly different. They follow a same trend until a strain of $3.6 \%$. Above this value, the relative volume of damage for the nonaged specimen slightly increases, until a value of $0.40 \times 10^{-3}$ at $5.07 \%$ of strain. The relative volume of damage for the wateraged specimen significantly increases from $7 \%$ of strain and reaches a value of $8.32 \times 10^{-3}$ at $22.9 \%$ of strain. The hemp/Epolam composite deforms much more after the water ageing, and the appearance of a higher volume of damage is directly linked with the increase in the strain at break.

Fig. 12b presents the same relative volumes of damage plotted against the applied stress level reached for each loading cycle. The values of the ultimate stresses $\left(\sigma_{\mathrm{u}}\right)$ are indicated with the dotted lines. This graph shows that the development of the volume of damage is similar for the two samples until a maximum applied stress of $44 \mathrm{MPa}$. Then, the amount of damage in the water-aged sample rapidly increases until failure, while it develops slowly in the non-aged specimen. This illustrates the decrease in the stress at break due to water ageing. These data demonstrate the major influence of the water ageing on the development of damage during a tensile test for a plant fibre composite.

\section{Conclusions}

The influence of water ageing on the evolution of damage during tensile loading in woven hemp/epoxy composites was studied. First, the water absorption of several types of hemp/epoxy composites was measured. The gravimetric measurements of the immersed woven composite samples showed that the water absorption is influenced by the type of the resin but also by the fabric architecture. Moreover, the kinetics of absorption is better described by the Lamguir-type absorption model than by the Fickian model. After removing the specimens from water, the desorption at ambient temperature created a whitening of the material attributed to the appearance of damage. A specific analysis by means of X-ray microtomography has been performed on an immersed sample. The results showed that, during immersion, no damage is seen but, from the beginning of desorption, damage appears and develops without any applied loading. This damage 
essentially comes from the differential shrinkage between the different constituents of the materials while drying. This creates cracks at the yarn/matrix interface.

The effect of the water ageing on the tensile properties of selected specimens was analysed. Tensile tests revealed a significant decrease in the Young's modulus and the ultimate tensile strength, and a noticeable increase in the strain at break for the \pm 45 hemp/epoxy composite. Therefore, an original testing, combining tensile test and X-ray microtomography, was performed on a \pm 45 woven hemp/epoxy composite material. The analysis of the pictures enabled us to quantify the volume of damage inside the material during tensile loading, with and without water ageing. The appearance and the development of damage in the specimens were observed and the volumes of damage for each applied stress level were quantified. The results show that the evolution of the volume of damage is completely different between the non-aged and the water-aged hemp/epoxy composites. At the last loading cycle before the failure, the relative volume of damage in the water-aged sample is more than twenty times higher than in the non-aged specimen.

This work shows how the mechanisms of deformation and damage of plant fibre composites are governed by their moisture exposure history. The results obtained demonstrate that during a tensile test the damage created at the desorption is coupled with the damage due to the mechanical loading. The conditions of testing of plant fibre composites are therefore crucial.

\section{Acknowledgment}

The authors thank the Région Poitou-Charentes for its financial support. This work was partially funded by the French Government program "Investissements d'Avenir" (EQUIPEX GAP, reference ANR-11-EQPX-0018).

\section{References}

[1] Madsen B, Hoffmeyer P, Lilholt H. Hemp yarn reinforced composites - II. Tensile properties. Compos Part Appl Sci Manuf 2007;38:2204-15. doi:10.1016/j.compositesa.2007.06.002.

[2] Goutianos S, Peijs T, Nystrom B, Skrifvars M. Development of flax fibre based textile reinforcements for composite applications. Appl Compos Mater 2006;13:199-215. http://dx.doi.org/10.1007/s10443-006-9010-2.

[3] Faruk O, Bledzki AK, Fink H-P, Sain M. Biocomposites reinforced with natural fibers: 2000-2010. Prog Polym Sci 2012;37:1552-96. http://dx.doi.org/ 10.1016/i.progpolymsci.2012.04.003.

[4] Fotouh A, Wolodko J, Lipsett M. Isotherm moisture absorption kinetics in natural-fiber-reinforced polymer under immersion conditions. J Compos Mater 2015;49:1301-14. http://dx.doi.org/10.1177/0021998314533366.

[5] Doan T-T-L, Brodowsky H, Mäder E. Jute fibre/epoxy composites: Surface properties and interfacial adhesion. Compos Sci Technol 2012;72:1160-6. doi:10.1016/j.compscitech.2012.03.025.

[6] Newman RH. Auto-accelerative water damage in an epoxy composite reinforced with plain-weave flax fabric. Compos Part Appl Sci Manuf 2009;40:1615-20. http://dx.doi.org/10.1016/i.compositesa.2009.07.010.
[7] Assarar M, Scida D, El Mahi A, Poilâne C, Ayad R. Influence of water ageing on mechanical properties and damage events of two reinforced composite materials: Flax-fibres and glass-fibres. Mater Des 2011;32:788-95. http:/l dx.doi.org/10.1016/i.matdes.2010.07.024.

[8] Marcovich NE, Reboredo MM, Aranguren MI. Moisture diffusion in polyesterwoodflour composites. Polymer 1999;40:7313-20. http://dx.doi.org/10.1016/ S0032-3861(99)00093-2.

[9] Dhakal HN, Zhang ZY, Richardson MOW. Effect of water absorption on the mechanical properties of hemp fibre reinforced unsaturated polyester composites. Compos Sci Technol 2007;67:1674-83. http://dx.doi.org/ 10.1016/i.compscitech.2006.06.019.

[10] Azwa ZN, Yousif BF, Manalo AC, Karunasena W. A review on the degradability of polymeric composites based on natural fibres. Mater Des 2013;47:424-42. http://dx.doi.org/10.1016/j.matdes.2012.11.025.

[11] Perrier A, Touchard F, Chocinski-Arnault L, Mellier D. Influence of water on damage and mechanical behaviour of single hemp yarn composites. Polym Test 2017;57:17-25. http://dx.doi.org/10.1016/i.polymertesting.2016.10.035.

[12] Graupner N, Beckmann F, Wilde F, Müssig J. Using synchroton radiation-based micro-computer tomography (SR $\mu-C T$ ) for the measurement of fibre orientations in cellulose fibre-reinforced polylactide (PLA) composites. J Mater Sci 2014;49:450-60. http://dx.doi.org/10.1007/s10853-013-7724-8.

[13] Di Giuseppe E, Castellani R, Dobosz S, Malvestio J, Berzin F, Beaugrand J, et al. Reliability evaluation of automated analysis, 2D scanner, and microtomography methods for measuring fiber dimensions in polymerlignocellulosic fiber composites. Compos Part Appl Sci Manuf 2016;90:320-9. http://dx.doi.org/10.1016/j.compositesa.2016.07.020.

[14] Ragoubi M, George B, Molina S, Bienaimé D, Merlin A, Hiver J-M, et al. Effect of corona discharge treatment on mechanical and thermal properties of composites based on miscanthus fibres and polylactic acid or polypropylene matrix. Compos Part Appl Sci Manuf 2012;43:675-85. http://dx.doi.org/ 10.1016/i.compositesa.2011.12.025.

[15] Martin N, Mouret N, Davies P, Baley C. Influence of the degree of retting of flax fibers on the tensile properties of single fibers and short fiber/polypropylene composites. Ind Crops Prod 2013;49:755-67. http://dx.doi.org/10.1016/i. indcrop.2013.06.012.

[16] Rask M, Madsen B, Sørensen BF, Fife JL, Martyniuk K, Lauridsen EM. In situ observations of microscale damage evolution in unidirectional natural fibre composites. Compos Part Appl Sci Manuf 2012;43:1639-49. http://dx.doi.org/ 10.1016/i.compositesa.2012.02.007.

[17] de Vasconcellos DS. Comportement en fatigue avant et après impact de composites tissés chanvre/époxy. PhD thesis, ENSMA, 2013.

[18] Shen C-H, Springer GS. Moisture absorption and desorption of composite materials. J Compos Mater 1976;10:2-20.

[19] Carter HG, Kibler KG. Langmuir-type model for anomalous moisture diffusion in composite resins. J Compos Mater 1978;12:118-31. http://dx.doi.org/ 10.1177/002199837801200201.

[20] Bonniau P, Bunsell AR. A comparative study of water absorption theories applied to glass epoxy composites. J Compos Mater 1981;15:272-93. http:// dx.doi.org/10.1177/002199838101500306.

[21] Christian SJ, Billington SL. Moisture diffusion and its impact on uniaxial tensile response of biobased composites. Compos Part B Eng 2012;43:2303-12. http://dx.doi.org/10.1016/j.compositesb.2011.11.063.

[22] Ramezani Kakroodi A, Kazemi Y, Rodrigue D. Mechanical, rheological, morphological and water absorption properties of maleated polyethylene/ hemp composites: effect of ground tire rubber addition. Compos Part B Eng 2013;51:337-44. http://dx.doi.org/10.1016/i.compositesb.2013.03.032.

[23] Scida D, Assarar M, Poilâne C, Ayad R. Influence of hygrothermal ageing on the damage mechanisms of flax-fibre reinforced epoxy composite. Compos Part B Eng 2013;48:51-8. http://dx.doi.org/10.1016/i.compositesb.2012.12.010.

[24] Kim HJ, Seo DW. Effect of water absorption fatigue on mechanical properties of sisal textile-reinforced composites. Int J Fatigue 2006;28:1307-14. http://dx. doi.org/10.1016/i.iifatigue.2006.02.018.

[25] Doroudgarian N, Pupure L, Joffe R. Moisture uptake and resulting mechanical response of bio-based composites. II composites Polym Compos 2015;36:1510-9. http://dx.doi.org/10.1002/pc.23058. 